\title{
A EDUCAÇÃO AMBIENTAL COMO DIREITO FUNDAMENTAL DO HOMEM
}

\author{
CECILIA SMANEOTO, DANIEL RUBENS CENCI, JESILDO MOURA DE LIMA
}

RESUMO: O estudo trata da Educação Ambiental como direito fundamental do homem, mostrando que o mesmo é parte da natureza e exerce papel principal de preservador, devido a sua racionalidade, para que a humanidade busque melhorar a sua relação com o planeta. 0 estudo baseou-se na pesquisa bibliográfica e utilizou-se da revisão da literatura e do método descritivo e comparativo, com pesquisa indireta. Discorre também sobre a historicidade da Educação Ambiental, da sua evolução conceitual e da legislação brasileira sobre Educação Ambiental. Discorre sobre os saberes ambientais, da emergência que do assunto e das ações e possibilidades para a preservação ambiental. Relaciona o papel da Educação Ambiental no contexto do desenvolvimento sustentável e da interdisciplinaridade intrínseca. Proporciona embasamento teórico sobre a problemática, utilizando-se de autores renomados e que dão credibilidade ao assunto. Como conclusão relata as dificuldades encontradas na educação formal e das necessidades urgentes de construção de saber e racionalidade ambiental, via Educação Ambiental na formalidade e na informalidade.

Palavras Chaves: Educação Ambiental, homem, natureza.

ABSTRACT: The study talks about Environmental Education as a fundamental right for man, showing that the man himself is part of nature and plays a main role of preserving, due to his rationality, aiming humankind to enhance their relation with the planet. The study is based on bibliographical research and review of literature was also used, as well as descriptive and comparative methods, with indirect research. It also discusses the historicity about Environmental Education, its conceptual evolution and Brazilian legislation. It talks about environmental knowledge, the emergency of the issue and the possibilities to the environmental preservation. It relates the role of Environmental Education in the context of sustainable development and the intrinsic interdisciplinary. It provides theoretical basis on the issue, using renowned authors who lend credibility to the topic. As a conclusion, this study reports the difficulties faced in formal teaching and the urgent needs in constructing of knowledge and environmental rationality, via Environmental Education in formality and informality.

Key words: Environmental Education, man, nature.

\section{Considerações iniciais sobre o estudo}

Sabe-se que o impasse sobre a problemática ambiental não é assunto moderno, há muitas décadas já se fala sobre, e é um dos mais relevantes assuntos enfrentados pela humanidade hoje. O humano na suas práticas de exploração dos bens naturais vai aos poucos, ou aceleradamente em alguns itens, conscientizado ou não, gastando planeta, usando-se da natureza, e observa-se a cada dia a preocupação dos ambientalistas aumentar. Formar consciência 


\section{REMOA}

\section{Monografias Ambientais issn: 2236-1308}

ecológica, desenvolver sustentavelmente, preservar a natureza, garantir a biosfera para as próximas gerações, solucionar a crise ambiental e tantos outros títulos de mídias e estudos, remete-nos sempre a Educação Ambiental. È o caminho. É possível acreditar no calor desta perspectiva, por tantos motivos, mas principalmente pela enorme lista de nomes famosos que vem desenvolvendo o assunto. Pode-se Citar: Edgar Morin, Enrique Leff, Frijof Capra, Reinaldo Dias, José Carlos Barbieri, dentre outros.

Diante de cenário tão deprimente, com a emergência necessária, a racionalidade precisa e o saber a ser divulgado, é preciso questionar-se a maneira que a Educação Ambiental pode contribuir para a formação ecológica e de desenvolvimento sustentável e com pretensões de chegar a contribuir a idéia de cidadania ambiental.

O presente estudo tem objetivos claros a serem alcançados, com proposições de buscar junto a autores respostas de como poderão ser alcançados resultados através da Educação Ambiental que possam contribuir para a melhoria da condição exposta do meio ambiente em que se encontra. Serão discorridos os pensamentos de vários autores, sempre trazendo formas de relevância e comprovação teórica.

\section{Metodologia}

Os procedimentos metodológicos técnicos tratam esse estudo como uma pesquisa de documentação indireta, especificamente da revisão bibliográfica utilizando-se a mesma do método descritivo e do método comparativo, a fim de contribuir com mais de um pensamento a respeito da questão educativa ambiental.

\section{A Educação Ambiental e a sua história}

Em todo estudo faz-se importante falar sobre o caminho em que caminhou e caminha o tema em questão, para um entendimento apropriado do saber e uma melhor possibilidade de contribuição posterior do autor e de seus leitores. A educação Ambiental tem acontecimentos históricos e populares, que a caracterizam como uma problemática a ser desenvolvida. Já em 1864, George Perkin Marsch publica um livro com o título "O homem e a natureza: ou geografia física modificada pela ação do homem" que traz no tema a previsão do esgotamento de recursos naturais do planeta terra. Porém, a preocupação com o meio ambiente restringia-se aos estudos dos naturalistas amantes da natureza.

Segundo Dias (2004), no Brasil as primeiras manifestações de preocupação com a extração dos recursos naturais do país por estrangeiros foram ministradas por José Bonifácio de Andrada e Silva, ministro do Reino e dos Negócios Estrangeiros no final do século XVIII.

No início de 1945, a expressão "estudos ambientais" começava a ser utilizada em unidades de ensino na Grã-Bretanha, prevendo a grande catástrofe que viria ocorrer em 1952, quando o ar densamente poluído mata 1600 pessoas em Londres.

Para Lustosa, May e Vinha (2003), foi na segunda metade do século XIX começou-se a perceber a nível mundial a degradação ambiental e suas catastróficas consequências, surgiram 
estudos e as primeiras manifestações no sentido de se conseguir métodos que pudessem diminuir os danos ao ambiente, como os estudos do Clube de Roma, que lançou o livro "Limites de crescimento" (The limits to growth), fazendo um diagnóstico dos recursos terrestres concluindo que a degradação ambiental é resultado da falta de uma política de natalidade o que acarretou em um demasiado crescimento populacional.

Nos anos 60 Rachel Carson, com sua famosa obra "A Primavera Silenciosa", trouxe a consciência ambiental, se expandindo nos anos 70 depois da Conferencia das Nações Unidas sobre o Meio Ambiente, e em Estocolmo em 1972. Momento marcado para os limites da racionalidade econômica e os desafios da degradação ambiental ate o projeto civilizatório da modernidade. Dias (2004) também aborda que neste mesmo período no Brasil, criava-se a associação gaúcha de proteção ao ambiente natural - AGAPAN, mesmo o Brasil não tendo uma legislação ambiental, a AGAPAN começava uma longa e dolorosa caminhada contra iniciativas de alto potencial de degradação ambiental, como o Projeto Carajás e a Usina Hidroelétrica de Tucuruí. Em 1972, ocorre a Conferência da Organização das Nações Unidas (ONU) sobre o Meio Ambiente (consagrada "Conferência de Estocolmo") reunindo representantes de 113 países, para estabelecer uma visão global sobre a orientação para o homem preservar o meio ambiente.

Em 1983, a Organização das Nações Unidas cria uma comissão sobre o meio ambiente e o desenvolvimento que ficou conhecida mundialmente como Comissão Brundland, por ser presidida pela primeira ministra da Noruega, Gro Harlem Brundtland. Esta comissão passa a ter como objetivos principais: discutir as questões críticas sobre o meio ambiente, reformular propostas de abordagem e propor formas de cooperação internacional, com o propósito de orientar os países a desenvolverem ações de conscientização nas escolas, nas empresas e nos meios de comunicação. Conforme o relatório Brundland, os estados foram incumbidos de desenvolver ações que: limitasse o crescimento populacional, garantisse a alimentação dos seres humanos a longo prazo, preservasse a biodiversidade e os ecossistemas, diminuísse o consumo de energia, aumentasse a produção industrial de países não industrializados com tecnologias ecologicamente corretas, controlasse a urbanização e ações que interligassem o campo e as cidades menores.

Segundo Barbieri (1997), foi então que em 1992 aconteceu no Rio de Janeiro o mais importante foro mundial já realizado pela Conferência das Nações Unidas sobre o meio ambiente e o desenvolvimento, onde surgiu então a Agenda 21, que é um documento assinado por 179 países. A Agenda 21 não se restringe às questões ligadas á preservação e conservação do meio ambiente, ela considera ao mesmo tempo: a preservação do meio ambiente, o desenvolvimento social e o desenvolvimento econômico. A Agenda 21 viabiliza o desenvolvimento sustentável aliada à responsabilidade social e ao consumo consciente. É um programa de ações baseados em 40 capítulos, que pode ser adotado como escala global, nacional e local e conta com o apoio da ONU, dos governos, e da sociedade civil em todas as áreas que as ações humanas podem impactar ao meio ambiente. O capítulo 36 da Agenda 21 fala na promoção do ensino, da conscientização e do treinamento, pregando a reorientação do ensino no sentido do desenvolvimento, o aumento da conscientização pública e a promoção de treinamento da mão-de-obra qualificada a gerenciar o meio ambiente. Questão da fauna e da flora facilmente sensibiliza a população, principalmente crianças e jovens. Mudanças de comportamento exigem tempo, discurso de proteção à fauna e flora já está incorporada a cultura a população brasileira, mas as ações ainda deixam muito a desejar e problemas sociais precisam ser resolvidos para garantir sucesso às campanhas de educação ambiental. 
Nos caminhos percorridos da educação Ambiental, pode-se dizer que a Agenda 21 veio contribuir com todos os segmentos da sociedade, proporcionando um meio, uma ferramenta, uma forma de conduzir ações que sensibilizam os cidadãos para a prática educativa em favor da preservação do meio ambiente e de um desenvolvimento sustentável.

\section{A Educação Ambiental, seus conceitos e os diversos olhares}

A evolução dos conceitos de Educação Ambiental surgiu em decorrência da preocupação do homem com a crise do meio ambiente que ameaça a qualidade da existência humana, das presentes e futuras gerações. Com este propósito, demonstrando sua abrangência, também o seu significado, seguem informações acerca da Educação Ambiental no mundo.

Para Dias (2004), a evolução dos conceitos de Educação Ambiental acompanhou a evolução do conceito de meio ambiente. Em 1969 a Educação Ambiental era considerada um processo que deveria resumir-se à formação de cidadãos, para que eles pudessem resolver possíveis problemas relacionados ao ambiente biofísico.

Em 1970 iniciou-se o uso da expressão Educação Ambiental nos Estados Unidos. "environmental education", que foi a primeira nação a aprovar uma lei sobre Educação Ambiental. Dias (2004), diz que nesta época a União Internacional da Natureza definiu a Educação Ambiental como "um processo de reconhecimento de valores e classificação de conceitos, voltados para o desenvolvimento de habilidades e atitudes necessárias á compreensão e apreciação das interrelações entre o homem, sua cultura e seu entorno biofísico".

Em 1972 a Educação Ambiental era entendida como uma ferramenta de desenvolvimento de preocupação com o meio ambiente, a partir de um entendimento das relações do homem com o ambiente e sua vida, isto conforme Mellows apud Dias (2004). Já para Minini apud Dias (2004), em 2000, a Educação Ambiental trás as pessoas uma consciência crítica e mundial do ambiente, para confirmar valores e desenvolver ações que permitiam ao ser humano adotar uma posição consciente e participativa, a respeito da utilização dos recursos naturais, visando a melhoria da qualidade de vida, acabar com a pobreza e com o consumismo.

No final da mesma década realizou-se, em Tbilisi, na Geórgia, antiga União Soviética, a I Conferência Intergovernamental sobre Educação Ambiental, organizada pela Unesco, em colaboração com o PNUMA. O evento foi e é considerado uma referência na evolução da Educação Ambiental, haja vista que foi a mola propulsora para que a referida educação passasse a se constituir uma proposta pedagógica de fato, objetivando transformar a maneira de o homem pensar, agir e viver, e, dessa forma torná-lo um defensor das causas ambientais e do lugar em que vive. Com este norte a Recomendação $n$ 1, letra $b$, da conferência, define que "a Educação Ambiental é o resultado de uma reorientação e articulação de diversas disciplinas e experiências educativas que facilitam a percepção integrada do meio ambiente, tornando possível uma ação mais racional e capaz de resolver as necessidades sociais". Tal evento é considerado como o prolongamento da Conferência de Estocolmo (1972), pois confirmou e reiterou os princípios lá estabelecidos, especialmente a Recomendação no 96, que destaca a importância da Educação Ambiental como elemento crítico par ao combate à crise que atinge o meio ambiente.

Ainda segundo Dias (2004), a Educação Ambiental pretende desenvolver conhecimento, compreensão, habilidades e motivação, para adquirir valores e atitudes, indispensáveis para resolver os problemas ambientais com soluções sustentáveis. 
Segundo Rosa (2006) conceitos mais diversificados ocorreram ainda em outras partes do universo, redundantes e importantes, como se pode citar a não evolução do conceito ocorrido no Brasil ao publicar via Ministério da Educação e Cultura (MEC), em 1978, um documento colocando a disciplina de ecologia nos ensinos de 10 e 20 graus, que de maneira reducionista, dispunha o ensino da Educação Ambiental acondicionada à disciplina de ciências biológicas. Isso fez causa de indignação e revolta nas instituições brasileiras envolvidas com a um Educação Ambiental centrada e interdisciplinar, baseada no desenvolvimento do saber do homem.

Nas décadas de 80 e 90, do século 20, diz Carvalho (2004), que com o avanço da consciência ecológica, a Educação Ambiental cresceu e se tornou um instrumento indispensável p\ra o desenvolvimento sustentável do planeta. Para cuidar do planeta precisamos todos passar por uma alfabetização ecológica e rever nossos hábitos de consumo.

A definição oficial de educação ambiental, do Ministério do Meio Ambiente: "Educação ambiental é um processo permanente, no qual os indivíduos e a comunidade tomam consciência do seu meio ambiente e adquirem conhecimentos, valores, habilidades, experiências e determinação que os tornam aptos a agir - individual e coletivamente - e resolver problemas ambientais presentes e futuros".

A Educação Ambiental pode ser formal, que é um processo institucionalizado que ocorre nas unidades de ensino, ou informal e se caracteriza por sua realização fora da escola, envolvendo flexibilidade de métodos e de conteúdos e um público alvo muito variável em suas características (faixa etária, nível de escolaridade, nível de conhecimento da problemática ambiental, etc.).

Em suma, o conceito de Educação Ambiental é dinâmico, pois acompanha a evolução do conceito de meio ambiente, que está atrelada ao modo como este foi e é percebido. Houve alterações relevantes no decorrer da história do ambientalismo para se adaptar á realidade e, assim tentar, mediante a formação do sujeito ecológico, promover o desenvolvimento sustentável.

\section{A educação, a emergência, a racionalidade e o saber ambiental}

Na decorrência de um estudo, embora se faça realizar historicidades em cima de fatos, não se pode deixar de refletir sobre o que rodeia os conceitos e essa história a respeito do tema. Não há como se discorrer sobre Educação Ambiental, sem que se façam alusões ao saber, a emergência e a racionalidade ambiental. Os direitos do homem a respeito da Educação estão elencados nesse contexto. Ele deve ser inserido á reflexão num entendimento amplo, respeitando o saber de cada um, a racionalidade e o tempo de desenvolvimento. Enrique Leff é um dos autores renomados que discorre amplamente sobre o assunto. Neste estudo, contemplaremos o saber dele e as excelentes reflexões que faz a respeito do assunto.

Leff (2009), diz que sem dúvida, a educação ambiental ainda está muito longe de penetrar e trazer novas visões de mundo ao sistema educativo formal. Os princípios e valores ambientais que promovem uma pedagogia do ambiente devem ser enriquecidos com uma pedagogia da complexidade, que induza os alunos a uma visão de multicasualidade e de interrelações de seu mundo nas diferentes etapas do desenvolvimento psicogenético, que gerem um pensamento crítico e criativo baseado em novas capacidades cognitivas.

Diz ainda, a questão ambiental emerge como uma crise de civilização. E que as rupturas desta crise questionam os paradigmas do conhecimento, bem como os modelos societários da 
modernidade, defendendo a necessidade de construir outra racionalidade social, orientada por novos valores e saberes; por modos de produção sustentados em bases ecológicas e significados culturais; por novas formas de organização democrática. Fala que esta mudança de paradigma social leva a transformar a ordem econômica, política e cultural, que, por sua vez, é impensável sem uma transformação das consciências e dos comportamentos das pessoas. Nesse sentido, a educação se converte em um processo estratégico com o propósito de formar os valores, as habilidades e as capacidades para orientar a transição na direção da sustentabilidade.

E Leff (2006), continua a refletir, afirma que a educação ambiental ainda está muito longe de penetrar e trazer novas visões de mundo ao sistema educativo formal. Os princípios e valores ambientais que promovem uma pedagogia do ambiente devem ser enriquecidos com uma pedagogia da complexidade, que induza os alunos a uma visão de multicasualidade e de interrelações de seu mundo nas diferentes etapas do desenvolvimento psicogenético, que gerem um pensamento crítico e criativo baseado em novas capacidades cognitivas.

Já quando se manifesta a respeito da emergência do assunto posto, diz que a emergência da questão ambiental como problema do desenvolvimento e a interdisciplinaridade como método para um conhecimento integrado são respostas complementares à crise da racionalidade da modernidade. Frente ao ideal do projeto científico fundado na racionalidade formal e instrumental, de obter um controle crescente do mundo, através de sua capacidade de predicação, determinação e simplificação, a educação ambiental incorpora as dimensões da complexidade, da desordem, desequilíbrio e da incerteza no campo do conhecimento, afinados com os princípios da ecologia e da termodinâmica de sistemas abertos.

A produção sustentável emerge, assim, como novo objeto científico interdisciplinar e a educação ambiental como um instrumento para a construção da racionalidade ambiental. A interdisciplinaridade foi um ponto de referência constante dos projetos educativos, sobretudo no âmbito universitário. Sem dúvida, os avanços teóricos, epistemológicos e metodológicos no terreno ambiental foram mais férteis no terreno investigativo que eficazes na condução de programas educativos.

E sabiamente discorre sobre a racionalidade ambiental e diz em sua obra "Saber Ambiental" (2009) que a mesma implica em uma nova teoria da produção, em novos instrumentos de avaliação e em novas tecnologias ecológicas apropriáveis pelos próprios produtores; incorpora novos valores que dão novo sentido aos processos emancipatórios que redefinem a qualidade de vida das pessoas e o significado da existência humana. As distintas vertentes da sustentabilidade terão, pois, importantes repercussões sobre as estratégias e os conteúdos da educação ambiental. Os efeitos sobre o processo educativo serão diferentes se o movimento para sustentabilidade global privilegia os mecanismos do mercado para valorizar a natureza e a mudança tecnológica para desmaterializar a produção e limpar o ambiente, ou se está baseado em uma nova ética e na construção de uma racionalidade ambiental. A racionalidade ambiental conjuga uma nova ética e novos princípios produtivos com o pensamento da complexidade requer um programa de educação ambiental compreensivo e complexo, aberto a um amplo espectro de atividades e atores.

Já Morin (2004), fala que reaprender é mudar as estruturas do pensamento, por isso é uma tarefa muito difícil. Diz também que reeducar a si próprio significa sair de uma minoria; significa que educadores sentem a necessidade do problema, e como desviantes, vão ajudar outros educadores a mudar. Morin e Leff, concordam entre si nas dificuldades da educação e do 


\section{REMOA}

\section{Monografias Ambientais issn: 2236-1308}

saber, do homem reaprender a sua condição de parte da natureza, e pensam igualmente que perpassa pela educação formal e informal a possibilidade de acontecer então a Educação Ambiental, construindo racionalidade ambiental.

$\mathrm{Na}$ educação formal básica, trata-se de vincular a pedagogia do ambiente a uma pedagogia da complexidade. Isto implica em revalorizar o pensamento crítico, reflexivo e propositivo frente às condutas automatizadas que são geradas pelo pragmatismo e pelo utilitarismo da sociedade atual.

O saber ambiental ocupa seu lugar no vazio deixado pelo progresso da racionalidade científica, como sintoma da sua falta de conhecimento e como sinal de um processo interminável de produção teórica e de ações práticas orientadas por uma utopia: A construção de um mundo sustentável, democrático, igualitário e diverso. A degradação ambiental se manifesta com o sintoma de uma crise de civilização, resultado da modernidade regida pela razão tecnológica sobrepondo a degradação da natureza. O saber ambiental está em processo de gestação, em busca de suas condições de legitimação ideológica, de concreção teórica e de objetivação prática.

A emergência do saber ambiental abriu novas frentes para o desenvolvimento das disciplinas sociais: a relação entre cultura e natureza, a complementaridade entre geografia e ecologia, a influência do meio na consciência e no comportamento social.

E nesse diálogo que nos faz refletir Leff (2004), podemos compreender que há uma emergência para o saber ambiental se fazer, a racionalidade ambiental é um processo que envolve educação ambiental e consciência humana a respeito do consumo e do desenvolvimento sustentável. Percebe-se também nas reflexões de Leff que o processo é demorado, lento, moroso, mas que será o processo que poderá trazer resultados mais significativos e que permaneçam para as gerações futuras como um bem proporcionado, que faz parte da cultura dos humanos.

\section{O Homem como parte da natureza}

No inicio da historia da humanidade a natureza sempre se mostrou impiedosa e indiferente em relação à existência do homem. Atualmente esse quadro se inverteu. Hoje é o homem que é uma ameaça à natureza. Os homens, devido à sua ganância por riqueza, não se importam com as agressões e transgressões que comete com sua antiga algoz.

Segundo Capra (1996), a visão romântica da natureza como "um grande todo harmonioso", na expressão de Goethe, levou alguns cientistas, a estender a sua busca de totalidade a todo o planeta, e a ver a Terra como um todo integrado, um ser vivo. E completa dizendo que a idéia da Terra como um ser vivo, espiritual continuou a florescer em toda a Idade Média e a renascença, até que toda a perspectiva medieval foi substituída pela imagem cartesiana do mundo como uma máquina.

A "consciência" animal o homem denomina instinto e ao seu "instinto" denomina consciência. Sua soberba o faz esquecer-se do que há de semelhante com o resto dos seres vivos da natureza e que a natureza trata todos de igual modo. Ao tomar a consciência como a coisa mais relevante que se pode pertencer à essência de um ser vivo o homem comete um erro gravíssimo, a saber: que a posse da consciência o faz mais importante que o resto dos animais e, com isso, a ignorar a relação intrínseca que tem com a natureza. 
O homem não esta acima da natureza e nem tão pouco abaixo dela. Ele é a natureza como parte integrante, ou seja, ele faz parte da natureza como todos os outros animais e está desse modo submetido as suas leis imutáveis. A consciência disso é de vital relevância para que o homem possa se prevenir dos efeitos devastadores da natureza e fazer um melhor usufruto dos seus benefícios e preservá-los para as futuras .

O homem não deve sentir medo da natureza. Ela não é seu algoz, mas sim sua auxiliar na luta pela sobrevivência. Já que a natureza deu ao homem a faculdade da inteligência, que a use com prudência em seu beneficio, mas sem esquecer que é parte integrante da natureza e que não está acima dela. A ciência e a filosofia serão de grande ajuda para o homem fazer escolhas e agir com consciência das possíveis reações da natureza.

Na obra de Capra (1996), intitulada "A Teia da Vida", o mesmo usa uma citação de llya Progogine, russo de nascimento, físico e químico, prêmio Nobel e professor na Universidade Livre de Bruxelas, "eu estava muito interessado no problema da vida... sempre pensei que a existência da vida está nos dizendo alguma coisa importante a respeito da natureza". Ainda cita Capra, que o que mais intrigava o professor, era o fato de que os organismos vivos são capazes de manter seus processos de vida em condições de não-equilíbrio.

As reflexões a respeito do homem como parte da natureza nos conduzem a pensar que necessário se faz uma volta ao entendimento dessa afirmação. Se for parte da natureza, não mais compreende isso, não mais age como tal, não mais respeita e a emergência do saber ambiental, se faz presente, a partir da racionalidade ambiental por meio da educação.

Não há bandidos a serem vencidos e sim hábitos de consumo e estilos de vida a serem repensados e modificados. O que ocorre, na verdade, é que realmente não precisamos "voltar para as cavernas" ou viver como índios para conservar a vida selvagem, tampouco necessitamos abrir mão de progressos tecnológicos. No entanto, o dito desenvolvimento sustentável, só é realmente possível fora de um sistema econômico baseado no consumismo desenfreado como principal meta. Mas não podemos deixar de admitir que vivemos em uma sociedade economicamente dirigida e isso é um fato e uma realidade com a qual temos que lidar de forma pragmática, sem utopias e ilusões pueris. É possível questionar as argumentações expostas aqui neste estudo, utilizando um verdadeiro arsenal de argumentos econômicos, políticos, sociais, históricos, filosóficos, éticos, mas não são capazes de provar com fatos incontestáveis que possam conservar a vida selvagem, mantendo uma sociedade de consumo desenfreado, bem como é virtualmente impossível preservar a natureza sem que ela forneça alguma lucratividade, portanto os argumentos dos que defendem estas duas posições extremadas (conservação sem abrir mão do crescimento ininterrupto neoliberal e preservação total sem que haja qualquer interferência humana na natureza) não são válidos, nem, muito menos científicos, pois não podem ser comprovados.

O homem faz parte da natureza, por isso interage com ela, interfere e sofre as interferências dela. Nada é mais natural do que isso e não é diferente do que ocorre com outras espécies. 
REMOA

\section{Monografias Ambientais issN: 2236-1308}

\section{A Lei e a Educação Ambiental - direito do homem}

Em 27 de abril de 1999, é promulgada a Lei 9.795, composta de 04 capítulos, que tratam da educação Ambiental, da política nacional de Educação Ambiental, da execução da política nacional de educação ambiental e por fim de disposições finais

A lei contempla alguns parâmetros importantes, como quando determina que as atividades vinculadas à Política Nacional de Educação Ambiental devem ser desenvolvidas na educação em geral e na educação escolar, quando conceitua por educação ambiental os processos por meio dos quais o indivíduo e a coletividade constroem valores sociais, conhecimentos, habilidades, atitudes e competências voltadas para a conservação do meio ambiente, bem de uso comum do povo, essencial à sadia qualidade de vida e sua sustentabilidade e quando determina os princípios básicos. São eles, o enfoque humanista, holístico, democrático e participativo, a concepção do meio ambiente em sua totalidade, considerando a interdependência entre o meio natural, o sócio-econômico e o cultural, sob o enfoque da sustentabilidade, o pluralismo de idéias e concepções pedagógicas, na perspectiva da inter, multi e transdisciplinaridade, a vinculação entre a ética, a educação, o trabalho e as práticas sociais, a garantia de continuidade e permanência do processo educativo, a permanente avaliação crítica do processo educativo, a abordagem articulada das questões ambientais locais, regionais, nacionais e globais, o reconhecimento e o respeito à pluralidade e à diversidade individual e cultural.

Os objetivos da lei estão implícitos também e privilegiam o desenvolvimento de uma compreensão integrada do meio ambiente em suas múltiplas e complexas relações, envolvendo aspectos ecológicos, psicológicos, legais, políticos, sociais, econômicos, científicos, culturais e éticos, a garantia de democratização das informações ambientais, o estímulo e o fortalecimento de uma consciência crítica sobre a problemática ambiental e social, o incentivo à participação individual e coletiva, permanente e responsável, na preservação do equilíbrio do meio ambiente, entendendo-se a defesa da qualidade ambiental como um valor inseparável do exercício da cidadania, o estímulo à cooperação entre as diversas regiões do País, em níveis micro e macrorregionais, com vistas à construção de uma sociedade ambientalmente equilibrada, fundada nos princípios da liberdade, igualdade, solidariedade, democracia, justiça social, responsabilidade e sustentabilidade, o fomento e o fortalecimento da integração com a ciência e a tecnologia e o fortalecimento da cidadania, autodeterminação dos povos e solidariedade como fundamentos para o futuro da humanidade.

O artigo 9o da Lei, no capítulo II, seção II, traz o entendimento da educação ambiental na educação escolar a desenvolvida no âmbito dos currículos das instituições de ensino públicas e privadas, englobando: a educação básica, a educação infantil, o ensino fundamental, o ensino médio, a educação superior, a educação especial, a educação profissional e a educação de jovens e adultos. Ainda na mesma seção, no Artigo 10, institui que a Educação Ambiental será desenvolvida como uma prática educativa integrada, contínua e permanente em todos os níveis e modalidades do ensino formal, que a educação ambiental não deve ser implantada como disciplina específica no currículo de ensino, que nos cursos de pós-graduação, extensão e nas áreas voltadas ao aspecto metodológico da educação ambiental, quando se fizer necessário, é facultada a criação de disciplina específica, que nos cursos de formação e especialização técnicoprofissional, em todos os níveis, deve ser incorporado conteúdo que trate da ética ambiental das atividades profissionais a serem desenvolvidas. 


\section{REMOA}

A seção III da Lei, no capítulo II, trata da inserção da Educação Ambiental nas esferas informais e diz que entendem-se por educação ambiental não-formal as ações e práticas educativas voltadas à sensibilização da coletividade sobre as questões ambientais e à sua organização e participação na defesa da qualidade do meio ambiente.

E ainda prevê em Parágrafo único. O Poder Público, em níveis federal, estadual e municipal, incentivará a difusão, por intermédio dos meios de comunicação de massa, em espaços nobres, de programas e campanhas educativas, e de informações acerca de temas relacionados ao meio ambiente, a ampla participação da escola, da universidade e de organizações nãogovernamentais na formulação e execução de programas e atividades vinculadas à educação ambiental não-formal, a participação de empresas públicas e privadas no desenvolvimento de programas de educação ambiental em parceria com a escola, a universidade e as organizações não-governamentais, a sensibilização da sociedade para a importância das unidades de conservação, a sensibilização ambiental das populações tradicionais ligadas às unidades de conservação, a sensibilização ambiental dos agricultores e o ecoturismo.

O capítulo III traz a definição da execução da lei, e diz que a mesma estará sob a responsabilidade de um OG - Órgão Gestor, este regulamentado pelo Decreto 4.281/02, de 25 de junho de 2002. A Execução acontecerá então pelo SISNAMA ${ }^{1}$, pelas instituições educacionais públicas e privadas dos sistemas de ensino, pelos órgãos públicos da União, Estados, Distrito federal e municípios, envolvendo entidades não governamentais, entidades de classe, meios de comunicação e demais segmentos da sociedade. Assim fica o Órgão Gestor, responsável pela coordenação da PNEA ${ }^{2}$, dirigido pelos Ministros do Estado da Educação e do Meio Ambiente. 0 artigo 3으 do decreto traz as competências do Órgão Gestor: avaliar e intermediar programas e projetos na área ambiental, observar as deliberações do $\mathrm{CONAMA}^{3} \mathrm{e}$ do $\mathrm{CNE}^{4}$, apoiar o processo de implementação e avaliação do PNEA em todos os níveis, sistematizar e divulgar diretrizes, estimular e promover parceiras públicas e privadas, promover intercâmbio de informações, indicar critérios e metodologias para avaliação de projetos ambientais, levantar, sistematizar e divulgar fontes de financiamento para projetos de Educação Ambiental, dentre outras.

\section{Considerações finais}

O texto apresenta uma reflexão sobre a Educação Ambiental como direito fundamental do homem, trazendo em suas considerações inicias, os métodos, objetivos e o sequencial a ser conduzido, inclusive citando autores referencias que sustentam este.

Discorre em seguida sobre o histórico da Educação Ambiental e as contribuições que os grandes encontros sobre o tema obtiveram em relação ao assunto. Mostra uma evolução no desenvolvimento do tema e com as referências de autores que contam essa história, bem como as diretrizes tiradas do evento, pode-se considerar que a problemática do meio ambiente e a melhoria das condições do plante, passam pela Educação.

\footnotetext{
${ }^{1}$ Sistema Nacional de Meio Ambiente

${ }^{2}$ Política Nacional de Educação Ambiental

${ }^{3}$ Conselho Nacional de Meio Ambiente

${ }^{4}$ Conselho Nacional de Educação
} 
Nos conceitos concedidos ao texto, autores renomados discorrem amplamente sobre o assunto e como autor principal do estudo Enrique Leff colabora falando de saber, racionalidade, emergência e Educação Ambiental. Engloba em seu pensamento, reflexões que sustentam o que traz o título deste, o direito do homem ao saber ambiental, a construção da racionalidade ambiental e da emergência que o assunto se põe. Fala do tempo que temos para que se faça acontecer e das dificuldades que são encontradas quando da formalidade de introspecção da Educação Ambiental. Da interdisciplinaridade necessária na educação formal e informal, sobre os grandes problemas causados pela globalização, usando-se de reflexões a cerca da construção de uma racionalidade ambiental ampla. Para Leff (2009), fica evidenciado, a partir dos anos 60, que a crise ambiental surge da irracionalidade ecológica dos padrões dominantes de produção e consumo, marcando os limites do crescimento econômico. Neste contexto, emerge uma consciência ambiental e na percepção desta crise ambiental, a apropriação do conceito de ambiente.

A partir do exposto, o conceito de ambiente define categorias de racionalidade e de saber ambiental, problematizando o avanço das ciências e da interdisciplinaridade, colocando à prova o seu sentido questionador, transformador e recriativo nos domínios do saber.

A partir da complexidade da problemática ambiental e dos múltiplos processos que a caracterizam o autor questiona a fragmentação e compartimentalização do conhecimento disciplinar, incapaz de explicá-lo e resolvê-lo. Desta forma, a construção de uma racionalidade ambiental implica a formação deste novo saber e a integração interdisciplinar do conhecimento para explicar o comportamento de sistemas socioambientais complexos.

A crescente complexidade e o agravamento dos problemas socioambientais, levaram a colocar a necessidade de reorientar os processos de produção e aplicação de conhecimentos, bem como a formação de profissionais capacitados para trabalhar no contexto desta complexidade, com o propósito de conduzir um processo de transição para o desenvolvimento sustentável.

Mas para que se faça valer a construção de uma educação interdisciplinar, "entendida como a formação de mentalidades e habilidades para apreender a realidade complexa", deve ser algo que ultrapasse a simples junção de cursos e matérias para elaborar um programa multitemático.

Mas apesar das limitações apresentadas até então, é necessário que a formação ambiental seja fortalecida como um instrumento de transformação social, o que implica em assumir com paixão e compromisso a criação de novos saberes e recuperar a função crítica, prospectiva e propositiva do conhecimento, gerando um saber eficaz e inventar utopias capazes de levar os processos de mudança histórica a ideais de igualdade, justiça e democracia.

Na continuidade do texto, expõe-se um diálogo sobre o homem como parte da natureza, onde Fritjof Capra valoriza as considerações da autora deste. Neste diálogo é fortemente posto a pensamento e o questionamento de como pode o ser humano se utilizar de sua própria construção, de sua parte, de seu lugar, de sua condição primária de vida. A Terra como mãe, como provedora de sua existência, o seu lugar, é a afirmação que nos remete a pensar na soberba desenfreada dos humanos em busca de um desenvolvimento que não mede o uso de recursos naturais. E por fim, é preciso reaprender o papel fundamental como parte dessa natureza, a consciência do que acontece e a ligação direta com a Educação Ambiental. 


\section{REMOA}

\section{Monografias Ambientais issN: 2236-1308}

A Educação Ambiental como direito fundamental do homem não podia deixar de tratar da legalidade a que estamos expostos a esse tema. O texto traz amplo debate sobre a Lei brasielira de Educação Ambiental, seus objetivos, seu conteúdo, a regulamentação, bem como o decreto que a regulamenta, instituindo e definindo como será a execução da mesma.

A relação do texto com a lei é clara, se é direito do homem a educação, pode-se concluir que a Educação Ambiental está inserida neste direito e que esse direito, diante do exposto, da realidade ambiental atual, é um direito fundamental, visto estar claro a emergência do assunto.

\section{Referências Bibliográficas}

BARBIERI, José C. Desenvolvimento e Meio Ambiente. As estratégias da Agenda 21. 4 ed. Petrópolis, Rio de Janeiro, Vozes, 1997.

CAPRA, Fritjof. A Teia da Vida. "The Web of Life". Tradução Newton Roberval Eichemberg. São Paulo: Cultrix AmanaKey, 1996.

CARVALHO, ISABEL Cristina de Moura. Educação Ambiental: a formação do sujeito ecológico. São Paulo: Cortez, 2004.

Conferência das Nações Unidas sobre Meio Ambiente e Desenvolvimento. Agenda 21. 3. ed. Brasília: Senado Federal, Subsecretaria de Edições Técnicas, 2001.

DECRETO 4281/02 - http://wwwmeioambeinte.caop.mp.pr.gov.br/modules/conteudo/conteudo.php?conteudo=7, acesso em 22 se agosto de 2011;

DIAS, Genebaldo Freire. Educação Ambiental: princípios e práticas. 9 ed. São Paulo: Gaia, 2004.

DIAS, Reinaldo. Gestão ambiental: responsabilidade social e sustentabilidade. São Paulo: Atlas, 2006.

GODOI, Chistiane K., MELLO, Rodrigo B., SILVA, Anielson B., Pesquisa Qualitativa em Estudos Organizacionais. Paradigmas, Estratégias e Métodos. 2 ed. São Paulo: Saraiva, 2010.

LEI 9795/99 - http://www.planalto.gov.br/ccivil_03/Leis/L9795.htm, acesso em 23 de outubro de 2011;

LEFF, Enrique. Educação ambiental e desenvolvimento sustentável. Rio de Janeiro: DP\&A, 1999.

. Epistemologia Ambiental. São Paulo: Cortez, 2002.

Racionalidade Ambiental: a reaproximação social da natureza. Rio de Janeiro: Civilização Brasileira, 2006. 555 p/ Tradução do texto original em língua espanhola, de 2004.

Vozes, 2009.

Saber Ambiental. Sustentabilidade, Racionalidade, Complexidade, Poder. 7. ed. - Rio de Janeiro:

MAY, Peter H.; LUSTOSA, Maria Cecília; VINHA, Valéria. Economia do Meio Ambiente: Teoria e Prática. 6. Ed. Rio de Janeiro: Elsevier, 2003.

MORIN, Edgar (participação de Marcos Terena). Saberes Locais, Saberes Globais. O olhar interdisciplinar. 4 ed. Rio de Janeiro: Garamound, 2004.

ROSA. Vladimir d`. A punibilidade às infrações ao meio ambinete e seus benefícios à Educação Ambiental. Porto Alegre: Imprensa Livre, 2006.

UNESCO. 1987. Congresso InternacionalUnesco/Pnuma sobre Educação e Formação Ambiental, Moscou, 1987. In: Educação e Interpretação Ambiental. Disponível em: HTTP:/WWW.mma.gov.br/port/sbf/dap/educamb.html, acesso em 13 de janeiro de 2011.

www.mma.gov.br, acesso em 12 de setembro de 2011. 